\title{
OSCILLATION OF A FORCED SECOND ORDER NONLINEAR DIFFERENTIAL EQUATION
}

\author{
SAMUEL M. RANKIN III
}

\begin{abstract}
Sufficient conditions are given which insure that every solution of $\left(a(t) y^{\prime}\right)^{\prime}+p(t) f(y) g\left(y^{\prime}\right)=r(t)$ has arbitrarily large zeros. We seem to have a partial answer to a question posed by Kartsatos [4]. An example is given illustrating the result.
\end{abstract}

Recently Keener [5], Skidmore and Bowers [8], Skidmore and Leighton [9], Rankin [7] and Tefteller [10] have investigated the oscillation and nonoscillation of solutions of the linear equations $\left(a(t) v^{\prime}\right)^{\prime}+p(t) v(t)=r(t)$. In each of the above papers the results have depended on the associated homogeneous equation $\left(a(t) u^{\prime}\right)^{\prime}+p(t) u(t)=0$. Thus, these results are restrictive in the sense that the methods are not extendible to the nonlinear case.

Here we will study the equation

$$
\left(a(t) y^{\prime}\right)^{\prime}+p(t) f(y) g\left(y^{\prime}\right)=r(t) .
$$

Graef and Spikes [1] have recently given conditions which insure that every strictly positive solution or strictly negative solution or solutions that have arbitrarily large zeros but are of one sign approach zero as $t$ approaches infinity. Their result extends a result of Hammett [2] for equation (1) when $g\left(y^{\prime}\right) \equiv 1$. Others who have investigated the behavior of solutions of (1) when $g\left(y^{\prime}\right) \equiv 1$ are Kartsatos [3], [4] and Londen [6]; Teufel [11] has investigated the case for $p(t) f(y) g\left(y^{\prime}\right)=h\left(t, y, y^{\prime}\right)$.

Our result gives sufficient conditions which guarantee that every solution of equation (1) is oscillatory. As usual, a solution $y(t)$ of $(1)$ is oscillatory if for each real number $a$, there exists a $b>a$ such that $y(b)=0$. Obviously, we are assuming that all solutions can be extended to infinity.

The following assumptions are made: $a(t), p(t)$, and $r(t)$ are continuous on $[0, \infty) ; f(x)$ and $g(x)$ are continuous on $(-\infty, \infty) ; a(t)>0$ and $p(t)>0$ on $[0, \infty)$ and

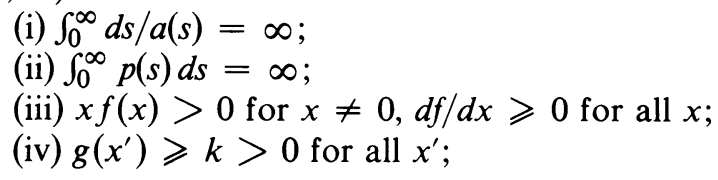

Presented to the Society, January 22, 1976; received April 14, 1975 and, in revised form, July $25,1975$.

AMS (MOS) subject classifications (1970). Primary 34C10.

Key words and phrases. Nonoscillatory solution, oscillatory solution, oscillation, nonlinear forced differential equations. 
(v) $\left|\int_{b}^{t}\left(\int_{b}^{s} d w / a(w)\right) r(s) d s\right|<M$ for all $t \geqslant b$ and all $b>0$.

(vi) There exists an increasing sequence $\left\{b_{n}\right\}$ with $\lim _{n \rightarrow \infty} b_{n}=\infty$ such that for each $n$,

$$
\lim _{t \rightarrow \infty} \int_{b_{n}}^{t}\left(\int_{s}^{t} d w / a(w)\right) r(s) d s=L_{n} .
$$

The numbers $L_{n}$ take on both positive, negative or possibly zero values for arbitrarily large $n$.

THEOREM 1. If conditions (iv)-(vi) are satisfied, then every solution $y(t)$ of equation (1) is oscillatory.

Proof. First, we notice that for each $n$,

$$
\begin{aligned}
& \int_{b_{n}}^{t}\left(\int_{s}^{t} d w / a(w)\right) r(s) d s \\
&=\left(\int_{b_{n}}^{t} d w / a(w)\right) \int_{b_{n}}^{t} r(s) d s-\int_{b_{n}}^{t}\left(\int_{b_{n}}^{s} d w / a(w)\right) r(s) d s
\end{aligned}
$$

and so by (i), (v), and (vi),

$$
\lim _{t \rightarrow \infty} \int_{b_{n}}^{t} r(s) d s=0 \text { for all } n .
$$

Now assume that there exists a solution $y(t)$ of equation (1) such that $y(t)>0$ on $\left[T_{0}, \infty\right)$ for some $T_{0}>0$. We have by integration of (1) from $b_{n}$ to $t$ for some $b_{n}>T_{0}$ that

$$
a(t) y^{\prime}(t)+\int_{b_{n}}^{t} p(s) f(y) g\left(y^{\prime}\right) d s=a\left(b_{n}\right) y^{\prime}\left(b_{n}\right)+\int_{b_{n}}^{t} r(s) d s .
$$

From (2) we have

$$
\lim _{t \rightarrow \infty}\left(a(t) y^{\prime}(t)+\int_{b_{n}}^{t} p(s) f(y) g\left(y^{\prime}\right) d s\right)=a\left(b_{n}\right) y^{\prime}\left(b_{n}\right) .
$$

Since $\int_{b_{n}}^{t} p(s) f(y) g\left(y^{\prime}\right) d s$ is nondecreasing with $t$, we see that $\lim _{t \rightarrow \infty} \int_{b_{n}}^{t} p(s) f(y) g\left(y^{\prime}\right) d s=\alpha$ where $\alpha=\infty$ or $\alpha$ is positive and finite. If $\alpha=\infty$, then $a(t) y^{\prime}(t)$ must approach $-\infty$ as $t$ approaches $\infty$ and this with (i) would imply that $y(t)$ is eventually negative. Therefore, $\alpha$ is finite.

Using (2) again we have that $\lim _{t \rightarrow \infty} a(t) y^{\prime}(t)=\beta$. The number $\beta$ must be zero, for if $\beta>0$ then $a(t) y^{\prime}(t) \geqslant c>0$ for all $t \geqslant T_{1}>T_{0}$ for some $T_{1}$. From (i) it would then be true that $\lim _{t \rightarrow \infty} y(t)=\infty$. Thus, by (iii) and (iv) there exists an $L>0$ such that $f(y) g\left(y^{\prime}\right)>L$ for all $t \geqslant T_{2}>T_{1}$ for some $T_{2}$. Integrating (1) from $T_{2}$ to $t$ we get

$$
a(t) y^{\prime}(t)-a\left(T_{2}\right) y^{\prime}\left(T_{2}\right)+L \int_{T_{2}}^{t} p(s) d s \leqslant \int_{T_{2}}^{t} r(s) d s .
$$

The right side of (4) is bounded as $t$ goes to infinity while the left side goes to $\infty$; hence, $\beta$ is not positive.

If $\beta<0$, then there would exist an $s>0$ such that $a(t) y^{\prime}(t)<-s$ for all 
$t \geqslant T_{3}>T_{0}$ for some $T_{3}$. This again leads to $y(t)$ becoming negative. Therefore, we must have $\lim _{t \rightarrow \infty} a(t) y^{\prime}(t)=0$, and from (3),

$$
\lim _{t \rightarrow \infty} \int_{b_{n}}^{t} p(s) f(y) g\left(y^{\prime}\right) d s=a\left(b_{n}\right) y^{\prime}\left(b_{n}\right) .
$$

From (5) and since $p(t) f(y(t)) q\left(y^{\prime}(t)\right)>0$ for $t \geqslant b_{n}$, we have that for each $b_{n}>T_{0}$

$$
\int_{b_{n}}^{t} p(s) f(y) g\left(y^{\prime}\right) d s \leqslant a\left(b_{n}\right) y^{\prime}\left(b_{n}\right) \text { for all } t \geqslant b_{n} .
$$

Assume that $n$ is such that $L_{n} \geqslant 0$ and let the positive number $\varepsilon$ be such that $L_{n}-\varepsilon>0$ if $L_{n}>0$ or $y\left(b_{n}\right)-\varepsilon>0$ if $L_{n}=0$. By integrating (1) twice from $b_{n}$ to $t$ we obtain

$$
\begin{aligned}
y(t)= & y\left(b_{n}\right)+\int_{b_{n}}^{t}\left(\int_{s}^{t} \frac{d w}{a(w)}\right) r(s) d s+a\left(b_{n}\right) y^{\prime}\left(b_{n}\right) \int_{b_{n}}^{t} \frac{d w}{a(w)} \\
& -\int_{b_{n}}^{t}\left(\int_{s}^{t} \frac{d w}{a(w)}\right) p(s) f(y) g\left(y^{\prime}\right) d s \geqslant y\left(b_{n}\right)+L_{n}-\varepsilon \\
& +\left(\int_{b_{n}}^{t} \frac{d w}{a(w)}\right)\left[a\left(b_{n}\right) y^{\prime}\left(b_{n}\right)-\int_{b_{n}}^{t} p(s) f(y) g\left(y^{\prime}\right) d s\right] \\
\geqslant & y\left(b_{n}\right)+L_{n}-\varepsilon=L^{\prime}>0 \text { for all } t \geqslant T_{4} \text { for some } T_{4}>T_{0} .
\end{aligned}
$$

Integrating (1) once more from $T_{4}$ to $t$ we have

$$
a(t) y^{\prime}(t)-a\left(T_{4}\right) y^{\prime}\left(T_{4}\right)+f\left(L^{\prime}\right) k \int_{T_{4}}^{t} p(s) d s \leqslant \int_{T_{4}}^{t} r(s) d s .
$$

Since $\lim _{t \rightarrow \infty} a(t) y^{\prime}(t)=0$, we see from (ii) that the left side of (6) approaches $\infty$ which contradicts the boundedness of $\int_{T_{4}}^{t} r(s) d s$.

Hence, our assumption that $y(t)>0$ on $\left[T_{0}, \infty\right)$ must be false (the case $y(t)<0$ is similar and will, therefore, be omitted), implying that $y(t)$ must be oscillatory.

EXAMPLE. Consider the equation

$$
y^{\prime \prime}+p(t) f(y) g\left(y^{\prime}\right)=e^{-t} \sin t .
$$

We have that $\left|\int_{b}^{t}(s-b) e^{-s} \sin s d s\right|$ is bounded for all $b$ and all $t \geqslant b$ and that

$$
\lim _{t \rightarrow \infty} \int_{b_{n}}^{t}(t-s) e^{-s} \sin s d s=L_{n}= \begin{cases}\sqrt{2} e^{-b_{n} / 2} & \text { if } n \text { even, } \\ -\sqrt{2} e^{-b_{n}} / 2 & \text { if } n \text { odd, }\end{cases}
$$

where $b_{n}=3 \pi / 4+n \pi, n=0,1,2, \ldots$ Thus if conditions (ii)-(iv) are satisfied then every solution of (7) is oscillatory. We can see that condition (vi) is critical by considering the equation

$$
y^{\prime \prime}+y=e^{-t} .
$$

Note that (i)-(v) are satisfied by (8) but (vi) is not. Equation (8) has the nonoscillatory solution $y(t)=e^{-t} / 2$. 
REMARKS. From our example, we see that our results handle functions $r(t)$ which are not considered in [11]. Thus, along with the results of [11] we seem to have at least a partial answer to a question posed by Kartsatos [4].

We note that for the example considered, the distance between $b_{n}$ and $b_{n+1}$ remained constant for all $n$ and that the $L_{n}$ 's alternated between strictly positive and negative values. These facts, however, were not needed in the proof of the theorem. In fact, the case $L_{n}=0$ for all $n$ would be acceptable. If $r(t) \equiv 0$, we would have this situation and therefore, it seems that our result is a natural extension of what is known for the equation $\left(a(t) u^{\prime}\right)^{\prime}$ $+p(t) f(u) g\left(u^{\prime}\right)=0$.

\section{BIBLIOGRAPHY}

1. John R. Graef and Paul W. Spikes, Asymptotic behavior of solutions of a second order nonlinear differentiai equation, J. Differential Equations 17 (1975), 461-476.

2. Michael E. Hammett, Nonoscillation properties of a nonlinear differential equation, Proc. Amer. Math. Soc. 30 (1971), 92-96. MR 43 \# 5106.

3. Athanassios G. Kartsatos, On the maintenance of oscillations of nth order equations under the effect of a small forcing term, J. Differential Equations 10 (1971), 355-363. MR 44 \#556.

4. _ Maintenance of oscillations under the effect of a periodic forcing term, Proc. Amer. Math. Soc. 33 (1972), 377-383. MR 48 \#859.

5. Marvin S. Keener, On the solutions of certain linear nonhomogeneous second-order differential equations, Applicable Anal. 1 (1971), no. 1, 57-63. MR 43 \#711.

6. Stig-Olof Londen, Some nonoscillation theorems for a second order nonlinear differential equation, SIAM J. Math. Anal. 4 (1973), 460-465. MR 48 \#1667.

7. S. M. Rankin, Oscillation theorems for second order nonhomogeneous linear differential equations, J. Math. Anal. Appl. (to appear).

8. Alexandra Skidmore and John J. Bowers, Oscillatory behavior of solutions of $y^{\prime \prime}+p(x) y$ $=f(x)$, J. Math. Anal. Appl. 49 (1975), 317-323.

9. A. Skidmore and Walter Leighton, On the differential equation $y^{\prime \prime}+p(x) y=f(x)$, J. Math. Anal. Appl. 43 (1973), 46-55. MR 47 \#3762.

10. S. C. Tefteller, Oscillation of second order nonhomogeneous linear differential equations, Siam J. Appl. Math. (to appear).

11. Hugo Teufel, Forced second order nonlinear oscillation, J. Math. Anal. Appl. 40 (1972), 148-152. MR 47 \#2137.

Department of Mathematics, Murray State University, Murray, Kentucky 42701 